\title{
PODEROSOS Y MALIGNOS: EL MUNDO DEL SERVICIO EN EL OBSCENO PÁJARO DE LA NOCHE ${ }^{1}$
}

\author{
María Francisca Ugarte Undurraga \\ Universidad de Santiago de Chile \\ franciscaugarteu@gmail.com
}

Palabras Clave: carnavalización, poder, servidumbre, José Donoso, El obsceno pájaro de la noche.

KEY WORDS: carnivalization, servitude, power, José Donoso, The Obscene Bird of Night.

¿Cómo no van a tener a sus patrones en su poder si les lavaron la ropa, y pasaron por sus manos todos los desórdenes y las suciedades que ellos quisieron eliminar de sus vidas?

José Donoso El obsceno pájaro de la noche

El obsceno pájaro de la noche, obra cumbre del chileno José Donoso, es de una complejidad fascinante, determinada por sus múltiples narradores, las transformaciones de sus personajes y la cantidad de líneas de lectura que derivan de hechos que pueden o no suceder, según se interprete el texto. Es por esto que ha sido leída y trabajada desde distintas perspectivas. Carmen Bustillo analiza la novela desde el punto de vista del barroco latinoamericano, poniendo énfasis en características del texto como la superabundancia y superposiciones, lo lúdico-grotesco, los desdoblamientos y transformaciones, los monstruos, máscaras,

1 Este artículo forma parte de un trabajo más extenso, la tesis de Licenciatura en Literatura Creativa La obscena Perra Amarilla, el poder oculto de la nana. 
disfraces y laberintos. Centrándose en el Mudito como personaje y como narrador, su hipótesis fundamental es que "la esencia del funcionamiento del espacio, de los personajes, e incluso del manejo del narrar es la metamorfosis incesante y el juego de espejos" 2 (222). También aludiendo a los laberintos de este libro, Augusto Sarrochi se adentra en el fuerte simbolismo de El obsceno desde un análisis esquemático de la estructura, el narrador, el espacio, los personajes (esquematizando sus rasgos principales y la relación entre ellos), los motivos (frustración, locura, culpa) y la plasmación mítica establecida por la conseja maulina, el mito del chonchón, el mito del imbunche y el mito del Minotauro en Creta. Además se detiene en los principales símbolos de la obra: las casas, el basural, los perros, las máscaras y disfraces, los juegos de azar y las dinámicas de entronización y destronamiento. Toda la investigación de Sarrochi está entendida desde la perspectiva del carácter laberíntico y demoníaco de la novela.

Otra autora que estudia la relación con el mito de esta obra es Lorena Amaro. Ella se centra en la actualización del mito, específicamente en la conseja maulina que determina la obra y cuyos personajes operan la actualización del mito en el presente narrativo. La conseja se entiende como fuente interminable de versiones de ese mito que las viejas cuentan, el "se dice". Amaro también reflexiona acerca de cómo la actualización se entrelaza con el imbunche y la relación entre el mito y el personaje del Mudito.

Por su parte, Miguel Ángel Náter propone un análisis que se mueve en los ejes del cuerpo (grotesco, deforme, enfermo e infectado de esquizofrenia y paranoia); la casa, como símbolo de la decrepitud y el sumergimiento en la decadencia; y el discurso novelístico. Estos tres ejes determinan la desintegración, la muerte y el espacio apocalíptico en el que se sitúa, finalmente, la novela.

Dentro del universo de posibilidades que ofrece la novela, en este artículo nos centraremos en el análisis del mundo del servicio y su relación ambivalente con el de los patrones. Específicamente, nos guiará la hipótesis que propone que las nanas y el servicio en general, son entes poderosos, que tienen tal poder -natural y sobrenatural-sobre sus patrones, que logran la extinción de la familia para la que trabajan.

La novela comienza relatando una conversación entre una monja, la madre Benita, y misiá Raquel Ruiz. La monja le está contando a Raquel que su nana, la Brígida ${ }^{3}$, ha

2 También en relación con el espejo, Ricardo Gutiérrez en José Donoso: Impostura e impostación. La modelización lúdica y carnavalesca de una producción literaria propone acerca de la relación especular de la cultura y el carnaval: "El contenido del carnaval es una imagen ya existente en la cultura, ya sea por el poder del rey (que se rebaja), el lenguaje sagrado (que se profana) o el decoro (que se subvierte), por lo cual es lícito hablar metafóricamente de una relación especular entre carnaval y cultura. El espejo no sólo duplica sino que invierte o deforma. El carnaval nunca reproduce a la cultura tal como la encuentra sino que practica una de las dos operaciones especulares sobre ella: la inversión constituye la parodia y la deformación constituye el grotesco, ambos modos de significación que Bajtín fundamenta en el carnaval" (28).

Se utilizará esta denominación porque es la misma que emplea Donoso: "la Brígida", "la María Benítez" para referirse a las empleadas, pero "misiá Raquel” o "Inés", 
muerto. A continuación aparece la Casa de Ejercicios Espirituales de la Encarnación de la Chimba, un antiguo convento de religiosas mantenido por la poderosa e influyente familia Azcoitía, ahora convertido en asilo para antiguas nanas ancianas, en decadencia y a punto de ser rematado al mejor postor y que es el lugar donde ha muerto la Brígida y vive la monja.

Tenemos, entonces, un lugar lleno de simbolismos -el ex convento con su capilla execrada, poblado por viejas nanas harapientas, intrigantes y de curiosa religiosidad, atendidas por monjas que se mimetizan con ellas y por un hombre al que llaman Muditorodeado de misteriosas leyendas de santas y brujas, y sumergido en una profunda decadencia corruptora. La Casa podría ser un asilo más, una solución cómoda para los patrones de nanas muy viejas para el trabajo, sin embargo, el Mudito saca la voz para dar un dato escalofriante:

El poder de las viejas es inmenso. No es verdad que las manden a esta Casa para que pasen sus últimos días en paz, como dicen ellos. (...) Los patrones las mandan encerrar aquí cuando se dan cuenta de que les deben demasiado a estas viejas y sienten pavor porque estas miserables, un buen día, pueden revelar su poder y destruirlos (Donoso, El obsceno... 55).

Por otro lado, está misiá Raquel, una mujer de familia acomodada que lamenta profundamente la muerte de su antigua empleada. Quedan, así, establecidos dos mundos: el de las nanas y el de los patrones. Son dos mundos opuestos que tienen una arraigada interrelación que intentaremos dilucidar. Dos mundos que Donoso caracteriza mediante oposiciones binarias, tales como luz y sombra, razón y locura, belleza y fealdad y orden y caos.

El mundo del servicio se concentra en la Casa, que es una versión carnavalizada-según el concepto de carnaval que propone Mijaíl Bajtín y sistematiza Julia Kristeva ${ }^{4}$ de la casa de los patrones, la casa de la familia de clase alta. Este lugar es habitado por antiguas nanas y algunas monjas que supuestamente las cuidan, pero que terminan confundiéndose con ellas y creando una especie de masa homogénea de viejas que a veces funciona como personaje coral. Tienen rasgos comunes que el autor remarca en la siguiente cita:

Meica, alcahueta, bruja, comadrona, llorona, confidente, todos los oficios de las viejas, bordadora, tejedora, contadora de cuentos, preservadora de tradiciones y supersticiones, guardadora de cosas inservibles debajo de la cama, de desechos de

para las mujeres de clase alta, marcando así la diferencia entre ellas, y también entre el trato coloquial y el respetuoso.

Carnaval y literatura carnavalizada como un lugar donde el discurso oficial y el discurso sometido pueden dialogar, relativizarse e incluso invertirse. Según Kristeva: "Es decir, que dos textos entran en contacto en él, se contradicen en él y se relativizan en él (14)". Se entiende el carnaval como el espacio liberador donde son posibles inversiones como el rey feo. De esta forma es posible que el sometido se imponga sobre el sometedor, como sucede en El obsceno pájaro de la noche. 
sus patrones, dueña de las dolencias, de la oscuridad, del miedo, del dolor, de las confidencias inconfesables, de las soledades y vergüenzas que otros no soportan (Donoso, El obsceno... 178).

Esta es la "nana tipo", una descripción que se ajusta a cualquiera de las viejas de la Casa. Sin embargo, hay algunas que se destacan. Dentro de la carnavalización que encarna el asilo, la Brígida es la patrona, la reina de las nanas. La nana de toda la vida de misiá Raquel Ruiz tiene un olfato especial para los negocios. Es la nana capitalista, ella le pide a su patrón que invierta su dinero según sus instrucciones. Sabe cuándo comprar en la Bolsa, cuándo vender acciones y cuándo comprar oro. Después de la muerte del patrón, misiá Raquel se encarga de correr con el dinero y las propiedades de la Brígida. Parte como un favor, pero poco a poco, esto se va transformando en una actividad de tiempo completo, en un vicio, en un sometimiento de la patrona al manejo de las finanzas de la nana. En palabras de Raquel:

$\mathrm{Y}(\ldots)$ tenía que levantarme temprano para ir a efectuar tal o cual transacción, una casa, un terreno para la Brígida. Me dio sus poderes notariales, Madre Benita. Es terrible que a una la carguen con los poderes de otra. (...) Me delegaba a mí para que le hiciera las cobranzas de sus arriendos. Yo firmaba por ella los recibos, las escrituras de compraventa a mi nombre, yo trotaba a las notarías, a buscar un gásfiter de confianza (...) yo se lo hacía todo. (...) Me envicié corriendo de departamento en departamento, rabiando por un vidrio roto, pescando bronquitis en las casas de renta de la Brígida (...) mientras ella me esperaba en mi casa calefaccionada, siempre tranquila y compuesta con su moño gris tan soigné (Donoso, El obsceno... 260-261).

Este caso refleja claramente la carnavalización que hace que se inviertan las jerarquías de poder $^{5}$; la nana tiraniza a su patrona para que ésta le preste un servicio, en concreto, que sea la encargada de administrar sus propiedades y finanzas. Producto de esto, la Brígida logra una fortuna inmensa, ni ella tiene conciencia de su real magnitud. Sin embargo, esta mujer no gasta ni un peso y sigue trabajando para Raquel hasta que decide irse a vivir a la Casa con otras nanas. Y es en este lugar donde demuestra todo su poderío. Aquí tiene estatus, es consultada sobre los asuntos más importantes -como el embarazo milagroso de la Iris Mateluna- y tiene su propia nana, la Amalia. Pero la gran jugada de esta mujer, tan inteligente como poderosa, es su funeral. Todos sus recursos y energías estaban destinados a organizar secretamente un funeral de reina, que demostrara su superioridad entre las otras viejas por lo ostentoso, pero especialmente, por el cariño de sus patrones, quienes le habrían regalado este último homenaje a su nana querida. El gran proyecto de la Brígida fue que las otras asiladas creyeran que sus patrones la querían al punto de regalarle esa despedida. No quiso que nadie supiera que lo había organizado y

En relación con esto, Guillermo García-Corales plantea: "El discurso carnavalesco revisa las estructuras hegemónicas de la sociedad y relativiza los paradigmas solemnes de autoridad y verdad al propiciar una visión del mundo a través de la inversión de jerarquías de poder" (20). 
pagado todo ella, dejando instrucciones precisas para su patrona y toda la familia, y así despertar la máxima admiración entre sus pares. Al mismo tiempo, este funeral marca el sometimiento más completo por parte de Raquel a su nana, ya que la obliga a fingir amor. La mujer lo comenta con la madre Benita: "El funeral de la Brígida no fue regalo mío. (...) Costearse un funeral estupendo, no debérselo a nadie, planearlo en todos sus detalles, fue la obsesión de su vida. (...) Transformarme en este monstruo de amor que no soy fue el lujo que se compró con su fortuna" (Donoso, El obsceno... 264). Una posible explicación para este sometimiento voluntario de la patrona a la nana -además de representar un juego, una forma de llenar las horas de su vida desocupada- viene dada por los planteamientos de Michel Foucault acerca del poder: "Lo que hace que el poder agarre, que se acepte, es simplemente que no pesa solamente como una fuerza que dice no, sino que de hecho va más allá, produce cosas, induce placer, forma saber, produce discursos" (193). Hay algo prácticamente irresistible en el poder de la Brígida para Raquel. En cuanto a la empleada y su interés en el funeral fastuoso regalado por Raquel, no hay un afán sentimental atrás de esto, pues a la Brígida no le interesa que su patrona la quiera, le interesa que las otras nanas piensen que su patrona la quiere. Esto es lo que determina su estatus y su poder dentro de la Casa y sobre Raquel.

Otra nana poderosa es la María Benítez, cocinera de don Clemente de Azcoitía -sacerdote jubilado que pertenece a la familia preclara que estructura todo el relato, y que termina siendo disuelta por el poder del mundo del servicio. Ella y su patrón representan el poder político. La María era quien preparaba los almuerzos que definían el futuro político del país. Es más, Donoso escribe que:

El rumor ciudadano hacía circular el cuento de que quien determinaba los acontecimientos políticos del país era una tal María Benítez, cocinera de toda la vida de don Clemente, cuya caricatura solía aparecer en un insolente pasquín ilustrado como la encarnación de la oligarquía, revolviendo con su cucharón descomunal la olla rotulada con el nombre del país (141).

Nuevamente hay una inversión de las jerarquías de poder. La cocinera, una sirviente, tiene poder político y a través de su trabajo, de sus comidas, logra influir en el acontecer nacional. En este caso, el poder no se ejerce directamente sobre su patrón, el sacerdote, sino que ambos se unen para potenciar su poder político. El poder se ejerce sobre todo un país. En este sentido, las jerarquías parecieran desaparecer y el poder político iguala a la nana y al patrón. Esta condición de relativa igualdad entre ambos se mantiene por un tiempo. Cuando envejecen, los dos terminan asilados en la Casa: la María, como su destino natural por ser nana vieja de algún Azcoitía; y don Clemente más o menos por las mismas razones: el antiguo convento es usado por los Azcoitía como un lugar para esconder lo vergonzoso, lo indeseable -nanas viejas y poderosas, hijas brujas o deshonrosamente embarazadas y tíos sacerdotes ancianos y seniles.

Sin embargo, una vez dentro de la Casa, empieza a operar la carnavalización y la inversión de las jerarquías. La María se hace más poderosa mientras que don Clemente pierde facultades progresivamente. Es así como ella termina en una posición de superioridad, miembro clave del selecto grupo de las siete viejas que comparten el 
secreto del embarazo milagroso de la Iris. Opera como curandera y bruja; es la meica que prepara ungüentos de todo tipo. Por otro lado, don Clemente, sumido en la senilidad, enloquece sin remedio y sin dignidad. Termina merodeando desnudo por la Casa -en su caso, esto es especialmente significativo: él, que tenía la investidura sacerdotal con el poder que eso implica, es despojado de todo, desnudado- y completamente perturbado. Muere alejado de su familia y provocando una mezcla de lástima y repulsión en las viejas que aseguran que su fantasma se aparece desnudo en los pasillos de la Casa, por lo que organizan rezos de rosarios para pedirle a Dios que al menos le conceda ropa a su ánima. Así, el sacerdote que decidía qué políticos gobernarían al país queda reducido a su mínima expresión, mientras que su cocinera se instala en una posición de poder.

Estos son algunos casos de nanas poderosas y de cómo ese poder es producto de la carnavalización. Pero, sin duda, las representaciones máximas del poder del mundo del servicio por sobre el de los patrones en El obsceno pájaro de la noche son la de la Perra Amarilla y la Peta Ponce.

La Perra Amarilla aparece por primera vez en el relato representada por la nana de la conseja maulina, leyenda estructural dentro de la novela que se repite en varias ocasiones y en distintas versiones según quién la narre. Según la versión de las viejas de la Casa, un cacique del Maule, antepasado de los Azcoitía, tenía varios hijos y una hija cuya madre había muerto al nacer, por lo que fue criada por su nana. Esta nana en el sentido más amplio (nodriza, madre, iniciadora) es inseparable de la niña, se dedica completamente a ella y el narrador la caracteriza con manos verrugosas. Este rasgo permite identificar a todas las encarnaciones de la nana y la Perra Amarilla a lo largo de la novela. Por otro lado, la niña rubia, hacendosa y cariñosa es la adoración de toda la familia. Sin embargo, la armonía inicial de ese mundo rural y familiar se rompe por una época de sequías y nacimientos de niños muertos o deformes. Entre los campesinos comienza a circular un rumor:

En las noches de luna volaba por el aire una cabeza terrible, arrastrando una larguísima cabellera color trigo, y la cara de esa cabeza era la linda cara de la hija del patrón. (...) La cabeza de la hija del patrón iba agitando enormes orejas nervudas como las alas de los murciélagos, siguiendo a una perra amarilla, verrugosa y flaca como su nana, que guiaba al chonchón hasta un sitio que los rayos del astro cómplice señalaban más allá de los cerros: ellas eran las culpables de todo, porque la niña era bruja, y bruja la nana, que la inició también en esas artes, tan inmemoriales y femeninas como las más inocentes de preparar golosinas y manejar la casa (Donoso, El obsceno... 32).

Estos rumores alcanzan tal importancia que terminan con la familia del cacique persiguiendo a la perra amarilla -álter ego brujeril de la nana de manos verrugosas- y al chonchón, para matarlos y acabar con los dichos que falsamente acusan a la niña. Encuentran a la nana, pero no pueden matarla, por eso la amarran a un tronco y la lanzan al mar, ya que arruinaría el campo enterrar a una bruja. Mientras, el padre entra en la pieza de su hija y se encuentra con el siguiente espectáculo: 
...La vieja yacía inmóvil en su lecho, embadurnada con ungüentos mágicos, los ojos entornados, respirando como si durmiera, o como si el alma se le hubiera ausentado del cuerpo. (...) La niña lloraba en la pieza donde su padre la dejó encerrada.

— ¡Nana! ¡Nanita! Que no la maten, papá, que no la maten, que la dejen volver a su cuerpo. Si no la matan, yo le juro que confieso todo... (Donoso, El obsceno... 34-35).

Luego de esta especie de confesión, la niña es encerrada por su padre en un convento de la capital. Nadie supo realmente qué fue lo que el padre vio en su hija cuando entró a su pieza. Hay quienes dicen que se encontró con la cabeza del chonchón uniéndose al cuerpo de su hija. Otra vertiente propone que el cacique vio a su niña pariendo el hijo de un peón, ya que la nana habría facilitado los amores entre la niña y el trabajador del fundo, causando así el embarazo y la correspondiente desgracia de la niña y su familia. Además, se dice que nunca pudieron matar a la Perra Amarilla y el pellejo que les presentaron al hacendado y sus hijos era de otro animal.

Esta primera nana de manos verrugosas ejerce un influjo maligno sobre la niña Azcoitía y ese influjo está dado y custodiado por la Perra Amarilla que opera como un ente sobrenatural que puede encarnarse sucesivamente en el tiempo y en otras nanas. Esta nana convierte en bruja o en un ente sobrenatural maligno, el chonchón, a la niña que se le había encomendado, con toda la carga negativa que eso tiene para la familia. Ella tiene el poder de corromper lo más puro. Además, el poder de la nana y la Perra Amarilla se expande fuera del ámbito de la casa: son capaces de afectar las cosechas e incluso los nacimientos de niños en toda la comarca regida por el padre.

La que podría llamarse - a ojos del mundo de los patrones- perversión de la niña pura que es la adoración de toda la familia, termina demostrando el poder de la nana: a pesar de que ella tiene un final deplorable, la niña bruja (o la hija adolescente que ha parido el hijo de un peón) es una mancha para la familia y debe ser encerrada en el convento que rige su tía. A partir de esa situación adversa para el mundo de los patrones, se crea otra versión de la conseja, más favorable para éstos: la niña no es bruja sino santa y, como tal, en uno de sus éxtasis místicos obra el milagro de impedir que el convento -que luego será la Casa de Ejercicios Espirituales de la Encarnación de la Chimba- se caiga durante un terremoto. El mismo milagro que servirá de asidero a la otra Inés ${ }^{6}$ para ir a pedir su beatificación a Roma. De esta forma, el mundo del servicio, y en especial la Perra Amarilla, sufre una especie de revés al no poder lograr la ruina de la familia, fortalecida ahora por esta supuesta santa. Quizás es por eso que vuelve a la carga con la segunda Inés de Azcoitía. La hermosa niña rubia de la conseja, la primera Inés de Azcoitía, es encarnada ahora por otra Inés, la mujer de Jerónimo de Azcoitía. La nana, en esta ocasión es la temible Peta Ponce. Acompaña a la niña desde pequeña y tiene una tremenda influencia sobre ella, tanto física como sicológica y sobrenatural. A propósito de esta relación, Laura Bocaz, en un artículo sobre la Peta Ponce basado en los apuntes de Donoso en los que prefigura al personaje, establece que: "la relación entre ambas

6 Se trata de Inés de Azcoitía, la mujer de Jerónimo de Azcoitía, quien viaja a Roma para conseguir la beatificación de su antepasada. 
mujeres es íntima y peculiar, de hecho, el autor cifra en su cuaderno como uno de los objetivos a desarrollar el "profundizar más -en sentido psicológico naturalmente- lo demoníaco de la relación Inés-Peta” (B9, NB 22: 120)" (130).

Un ejemplo claro de los alcances de esta relación aparece cuando antes de casarse, Inés le cuenta a su novio cuánto le debe a la Peta Ponce:

La Peta me salvó la vida.

Me moría, Jerónimo, me moría de algo que nadie era capaz de comprender ni curar. (...) Una noche, cuando sentí los dolores más espantosos, la Peta se levantó. (...) Dejé que la Peta me desnudara. Y acercando sus labios a mi vientre me los puso aquí, Jerónimo, justo en el foco del dolor y comenzó a chupar y a chupar, y a chupar hasta que mis dolores desaparecieron completamente con el último sorbo de la Peta en mi vientre. Me quedó algo como un vacío, aquí. (...) La Peta ha seguido sintiendo esos dolores míos toda la vida (Donoso, El obsceno... 154).

Lo que la joven ignora es que en esta maniobra, la vieja le arrebata su fertilidad y la deja literalmente con un vacío, como ella dice; incapaz de embarazarse. Solo puede lograrlo mediante actos semi sobrenaturales para concebir un niño monstruoso. Luego, cuando Inés comienza a desesperarse porque no queda embarazada y recurre a Peta buscando ayuda, ésta le propone la idea de una relación sexual mágica, idea que habría sido susurrada por la antepasada bruja en el oído de la Peta. Sin embargo, la antepasada de Inés y su nana no son las únicas brujas del relato, la Peta Ponce también lo es, tal como lo demuestra el episodio de los dolores de Inés. En palabras de Bocaz:

La brujería, por su parte, constituye uno de los rasgos que caracterizan desde el inicio de la obra a la Peta Ponce. Donoso señala: "La Peta, por lo demás, es como la reencarnación de muchas brujas populares, de muchas generaciones de brujería campesina" (B9, F7, NB 23: 17). (132).

Retomando el análisis, resulta que finalmente este plan confuso para el embarazo solo logra malos resultados para el mundo de los patrones: Jerónimo obtiene su heredero, un hijo deforme, inservible para continuar el apellido y que debe encerrarse. Así, la Peta y la Perra terminan con el apellido, pero para llegar a eso han debido usar toda su influencia sobre Inés. Ésta es tal que alcanza también a Jerónimo que desde el principio la ve como una enemiga poderosa de la que hay que alejarse y, sin embargo, no puede apartar a su mujer de ella. Inés utiliza los métodos femeninos más tradicionales, según Donoso: "cometió el pecado mortal de negarle su cuerpo a su marido" (155) trastornándolo hasta que "le hizo prometer (...) que jamás, por ningún motivo, la iba a separar de la Peta Ponce” (156).

Por último, en esta nueva versión también está el elemento más importante: la Perra Amarilla. Siempre está rondando a Inés y a la Peta, aparece como una perra verrugosa, flaca y hambrienta que ronda la casa de la familia, es perseguida por los cuatro perros negros de Jerónimo y defendida férreamente por Inés; está presente y posibilita la concepción de Boy, el niño monstruo; y aparece luego como parte de un juguete que ayuda a Inés a ganar al niño milagroso en la Casa y transformarse en la santa carnavalizada hacia el final del relato. Acerca de la Perra Amarilla, Sonia Montecino en Palabra dicha propone: 
Pareciera ser que en El obsceno pájaro de la noche, la perra amarilla nombra la naturaleza domesticada, pero también su insubordinación, por eso debe ser perseguida y reiteradamente sacrificada, asesinada. Asimismo, ella surge como la encarnación de lo animal en lo humano y, a la vez, como el polo de una serie de transformaciones del orden de la naturaleza al orden de lo construido socialmente (lo femenino, las clases, los status, etc.).

Pero asimismo pienso que la metáfora de la perra amarilla puede ser leída desde múltiples significados que rozan nuestra cultura mestiza: por un lado ella es una híbrida, una quiltra sin raza definida, sin linaje. Por otra parte, cristaliza el tránsito, el flujo permanente de la naturaleza a la cultura. Ella describe el periplo de las mutaciones, del desdoblamiento en que podemos ser una cosa u otra, perros que nos transformamos en personas, personas que nos transfiguramos en perros. Mas también la perra amarilla se instala como el opaco brillo de un movimiento mimético en donde todos, al menos en el deseo y la fantasía, podemos llegar a ser el otro que envidiamos y amamos. La perra, la nana, la bruja quieren ser Inés, la patrona, la hermosa. Ansia de imitación, de copia, de todo lo que ella no es: la perra es pobre, es sarnosa, es fea y flaca (68-69).

Y sin embargo, se podría agregar a esta cita que la Perra Amarilla es mucho más poderosa que la representación que ansía imitar. Es mucho más que todo eso y desde su posición sobrenatural logra que eso que es su opuesto, Inés, se asemeje a ella, se una a su poder para lograr un objetivo que va incluso en contra del mundo al que Inés pertenece. Hasta ese nivel logra manejarla.

Inés, la Peta y la Perra Amarilla forman una tríada poderosa y maligna, como una grotesca carnavalización de la Santísima Trinidad del catolicismo. La influencia de las dos últimas sobre la primera hace que finalmente la familia Azcoitía llegue a su disolución. Inés enloquece completamente y termina recluida en un manicomio; Jerónimo también pierde la cordura y muere creyendo ser un monstruo en la Rinconada. El último vástago de la familia, Boy, es un joven que reúne todas las deformidades posibles y busca pasar sus días escondido en la Rinconada, su paraíso personal, rodeado de monstruos y sin posibilidad de perpetuar la familia. El poder del universo del servicio logra someter y anular a los empleadores. Desde la perspectiva de su análisis que ya presentamos al comienzo de este trabajo, Lorena Amaro llega a una conclusión semejante:

Las mujeres y sirvientes, a su vez, ejercen poder: la novela nos presenta anverso y reverso de la dominación. Mujeres y sirvientes tejen los hilos en silencio. Pero su modo de apropiarse del poder se vincula con la magia de la Peta Ponce, con la irracionalidad, con la leyenda. Con la constante amenaza de las brujas: el imbunche (340).

A pesar de que las nanas son sus principales exponentes, existe otra parte del ámbito del servicio que también está presente en la novela. Se trata de la representación masculina del servicio, específicamente de Humberto Peñaloza, el secretario de don Jerónimo de Azcoitía.

La sexualidad del matrimonio Azcoitía está fuertemente mediada por sus servidores, en especial por la Peta Ponce, la Perra Amarilla y Humberto Peñaloza. Este último tiene el poder de activar la masculinidad de Jerónimo por medio de su mirada. El secretario 
está muy consciente del poder que posee y, tal como lo propone Miguel Ángel Náter: "Esa mirada que implica el origen de la existencia y el poder, es el contacto del ser con el mundo, además es la potencia sexual de don Jerónimo, y "el Mudito" desea que lo conviertan en imbunche para oponerse a que don Jerónimo se adueñe de su poder" (316).

Es decir, Humberto está dispuesto a ser imbunchizado - a tener todos los orificios del cuerpo cosidos y estar encerrado en sí mismo-, a quedar anulado como persona, antes que perder lo único que le da poder sobre su empleador: su mirada.

Este es uno de los rasgos con que el autor dota a los personajes que pertenecen al mundo del servicio: estar ligados a la sexualidad y desde ese punto, controlar o interferir en la sexualidad y fecundidad de sus patrones. En la lógica del discurso donosiano las nanas y sirvientes están inmersos en el mundo de lo oscuro y lo irracional, en oposición a los patrones. En este entendido, es casi natural que se relacionen con la sexualidad, ya que es parte del dominio de lo irracional y lo tabú, en especial dentro de la representación de las clases acomodadas. Michel Foucault ya ha hablado acerca de esta relación entre poder y sexualidad y cuerpo, y la influencia que Humberto y la Peta Ponce tienen sobre el matrimonio Azcoitía pareciera hacerse eco del filósofo cuando dice que: "Si el poder hace blanco en el cuerpo no es porque haya sido con anterioridad interiorizado en la conciencia de las gentes. Existe una red de bio-poder, de somato-poder que es al mismo tiempo una red a partir de la cual nace la sexualidad como fenómeno histórico y cultural” (166). O quizás es, simplemente, otra manifestación de un influjo mágico sobre estos personajes.

Mediante esta capacidad, el Mudito se configura como otro sirviente poderoso frente a sus patrones, "y al igual que las ancianas, ha ido a parar a la Casa, reducto de los desperdicios y de los seres marginados de la clase alta" (Náter 327). Porque, en palabras de Náter, este lugar está para "enclaustrar a los seres indeseados de la familia de los Azcoitía. La Casa ha sido construida con ese fin. Esos seres son sirvientes, pero también encarnan sus temores y debilidades, los cuales es necesario reprimir" (318). También se ha encerrado en la Casa a quienes no son sirvientes, pero de alguna forma representan algo incómodo y oscuro para esta familia, como la primera Inés de Azcoitía y don Clemente.

Los hombres Azcoitía en general, y Jerónimo en particular, detestan lo oscuro, lo anárquico e incomprensible. El mundo de los sirvientes es todo eso, pero en El obsceno pájaro de la noche, como se ha expuesto, ese mundo además está cargado con un componente de magia siniestra que causa aún más temor y repulsión en los pertenecientes a la clase alta. Es un ámbito que debe ser silenciado y escondido, encerrado. Sin embargo, es también un segmento poderoso y, por lo mismo, peligroso.

Aquí aparece otra de las características importantes y generales relacionadas con las nanas: la necesidad de esconder y reprimir. Tradicionalmente se espera que un buen sirviente doméstico haga su trabajo de manera eficiente y discreta, sin notarse. Sin embargo, en este caso el autor va un paso más allá, y en su libro se busca encerrar con una doble finalidad: esconder lo desagradable y anular el poder de los sirvientes manteniéndolos "a raya".

Esto lleva directamente al poder como característica principal del servicio en esta novela, como hemos revisado anteriormente. 
Parte del poder de las nanas está dado por eso que obtienen de sus patrones, la parte oscura de ellos que toman y llevan al mundo tenebroso que el servicio representa dentro de la novela que se está trabajando. Augusto Sarrochi lo plantea de la siguiente manera:

Según el narrador-Mudito las sirvientas se posesionan de sus patrones a través de sus años de servicio. En sus menesteres fueron usurpando algo integral de la personalidad, sobre todo al colocarse en su lugar para hacer algo que a los patrones les resultaba desagradable. La criada se relaciona siempre con la usurpación y tiene un carácter maléfico (167).

Este mismo autor propone que las relaciones entre la nana y la empleadora "se concretan en dos grandes motivos: la posesión de la vida de otra persona, y la reducción a la nada" (167). Y para ejemplificar esto utiliza el caso de misiá Raquel y su nana, la Brígida. En esta relación, los vínculos de dependencia están llevados al extremo en su inversión: finalmente Raquel depende por completo de la ocupación que la Brígida le ha impuesto.

Lo mismo sucede con Jerónimo y Humberto, de manera mucho menos radical y casi equilibrada, pero marcada por la usurpación, ya que entre ellos "se establece una relación de dependencia que va más allá de un enlace patrón-sirviente, y abarca el plano casi ontológico. (...) La usurpación es doble: Humberto substrae la potencia sexual de don Jerónimo, y éste roba al otro la fertilidad" (Sarrochi 171).

Lo que Sarrochi define en términos de usurpación, posesión y reducción puede entenderse también según el concepto de inversión de las jerarquías de poder que se ha propuesto con anterioridad. Esa inversión es, a su vez, otro de los aspectos más importantes de las nanas que desarrolla Donoso en esta novela.

Todos los sirvientes que aparecen son poderosos y en muchos de los casos, ese poder sobre sus patrones les otorga también un carácter malévolo y oscuro. Es por eso, y por la relación con la brujería y la mitología, que el mundo del servicio es todo lo decadente, lo execrable -como la capilla de la Casa-, lo oscuro y lo sucio. Y se presenta en una eterna dualidad con el mundo de las personas a las que sirven, la clase alta, luminosa, racional y ordenada.

Por lo tanto, para entender el funcionamiento de esta dinámica entre servido y servidor, hay que concebirla como un movimiento constante y dialéctico entre los dos mundos que se han explicitado. Estos dos mundos parecen ser completamente opuestos, ya que se presentan en relaciones binarias de luz y sombra, orden y caos, razón e irracionalidad, jerarquía y anarquía. Pero a pesar de ser opuestos, no pueden entenderse por separado porque funcionan como una unidad y son en la medida en que se relacionan.

La necesidad de unidad de estos dos mundos llega a límites insospechados, como sucede con Inés y la Peta Ponce, que son capaces de desafiar al orden fáctico masculino para impedir su separación. Esta es una forma de relación de los dos polos dentro de esta novela. Hay otros ejemplos en que la relación de estos dos mundos, además de ser indisoluble, está invertida, como lo muestra el caso de la Brígida y su señora. Este es el segundo tipo de relación entre sirvientes y empleadores. Con respecto a este tipo de relación, pero sin referirse a El obsceno pájaro de la noche sino que a Donde van a 
morir los elefantes, Michael Colvin afirma que en esa novela, los personajes de Maud y Josefina funcionan según el esquema de siervo y patrón:

... Cuando las dos se ponen en contacto una con otra, se revela una dinámica del poder que hace eco de la convivencia entre amo y sirviente en las obras anteriores de Donoso. En casi toda la narrativa donosiana se explora esta cohabitación intercambiable. A nivel superficial representa un vínculo jerarquizado en que los papeles de dueño y sujeto claramente se delinean. Pero sería erróneo ignorar las inversiones que se insinúan en actos aparentemente inofensivos, actos que constituyen la subversión de esa misma jerarquía (88).

Además, hay una tercera forma de relación de estos dos mundos que hace que los integrantes de ambos apuesten por una misma causa, lo que le da poder al servidor sin someter directamente al patrón. Es el caso de don Clemente y su cocinera. Si bien el protagonismo de la mujer en la toma de decisiones políticas que se caricaturiza en el pasquín le quita fuerza a la imagen de don Clemente como actor político, esto no va directamente en desmedro del sacerdote, sino que más bien le presta una especie de respaldo oculto para que siga desempañando su papel. Por eso, cuando el sacerdote se entera de los rumores que corren acerca del poder político de su cocinera, "entre carcajadas aseguraba:-¡Pero si no son más que almuerzos de familia!” (Donoso, El obsceno... 141) y así le baja el perfil a los dichos populares, sin anular el verdadero poder que ambos tienen.

Los anteriores son algunos casos en que se ven distintos niveles de inversión de las jerarquías de poder y de empoderamiento de la facción que debería ser más débil, la de las nanas.

Hay, sin embargo, otra situación más de estas inversiones y que está en la base de todas las descritas anteriormente. Es común a toda la servidumbre y se relaciona con las distintas visiones de mundo de los bandos que están involucrados. Es decir, cada uno de estos polos interpreta una misma realidad de acuerdo a su cosmovisión y según eso, la realidad puede ser manipulada o invertida.

Para ilustrarlo se puede tomar nuevamente como ejemplo la conseja maulina. Como se ha visto, esta conseja varía según quién la cuente y tiene una versión aceptada por los Azcoitía y otra que es la propia de las viejas, de la Peta Ponce y de los sirvientes del cacique que supuestamente participaron de los hechos.

Para el mundo de abajo, la niña y la nana eran brujas que causaban males en toda la comarca que recorrían de noche transformadas en chonchón y Perra Amarilla, respectivamente. Los sirvientes cuentan que frente a esta manifestación de la maldad y la magia de estas dos mujeres, el mundo de arriba, del cacique y sus hijos, decide que se debe castigar a quien ha sido la única y obvia incitadora de este mal: la nana. Además, la niña, víctima del influjo maligno de su nana, debe ser escondida en un lugar santo, quizás para redimirla de su cercanía con el mal. La lógica de este discurso calza perfectamente con la lógica que presenta el mundo de los sirvientes, representación de lo turbio, lo perturbador y lo irracional. Por eso es incuestionable que la maldad que afecta a la luminosa hija del patrón venga exclusivamente del representante más absoluto y odioso de ese mundo: la nana bruja, imposible de concebir en otro ambiente. 
Para contrarrestar esta fatídica vertiente de la conseja está la versión del otro mundo, del mundo de arriba. Se trata de una niña que llegó al convento -convenientemente se omiten las razones y circunstancias que llevaron a su arribo al lugar- que regía su tía y para el cual su padre construyó una nueva casa. Esta niña "murió a los veinte años en esta Casa, en olor de santidad" (Donoso, El obsceno... 295). Así esta conseja, transformada en una leyenda angélica sobre la posible beata Inés de Azcoitía, refleja la visión de mundo de los patrones. Porque la incomodidad de lo que vio el cacique y de lo que su poncho escondió al resto, al ser encerrada en la Casa, se convirtió en una niña-santa que obró un milagro. Fue así como "los Azcoitía se complacieron en tener, además de tantos héroes, una santa, o por lo menos una beata tan comentada, que adornara con su fervor el árbol de la familia" (Donoso, El obsceno... 296). Porque en su cosmovisión, lo que se adecua al orden es una integrante de la familia que sea santa y no bruja, que es algo relegado al mundo inferior de las nanas. Ese mundo inferior es profundamente temido por el de los patrones, al punto que les resulta insoportable. Sin embargo, depende de él para las labores domésticas cotidianas y para otro tipo de labores también, como hemos visto en los casos de inversión de las jerarquías de poder.

Por lo tanto, esta puede considerarse como otra de las constantes en la caracterización que el autor hace de los dos polos que se han descrito. Los sirvientes tienen una cosmovisión propia y opuesta a la de los patrones y muchas veces las representaciones que provienen de ellos afectan directamente al mundo luminoso. Como se ve hacia el final, incluso terminan infectándolo e instalando el caos. Por lo tanto, se asume que es esta cosmovisión la que prevalece, la del mundo del servicio.

El mundo de los sirvientes reflejado en la Casa representa asimismo lo obsceno y lo feo, según Náter: “don Jerónimo se caracteriza por el temor a lo feo, y por eso se deshizo de la Casa. También siente repugnancia por Boy y la Peta, quienes deben permanecer escondidos como elementos de lo obsceno" (313).

La fealdad del mundo oscuro se opone a la belleza del mundo de los patrones, encarnada de manera magistral en Jerónimo de Azcoitía, descrito como un ser excepcionalmente hermoso. Sin embargo, esa belleza también se ve invertida y carnavalizada en el momento de su muerte, cuando Jerónimo se ve a sí mismo como una persona horrible en comparación con la belleza invertida de los monstruos de la Rinconada y, sobre todo, por la belleza de su hijo Boy, el deforme.

En oposición con el orden que propone el mundo de los patrones, el mundo de los sirvientes es la representación del caos, ese caos que debe mantenerse a raya, pero a pesar de los esfuerzos de Jerónimo, termina colándose en su mundo perfecto y armónico:

Cuando don Jerónimo abre la cuna de Boy comienza la historia del caos, en la cual se desordenan la familia y la armonía. La deformidad del cuerpo se relaciona con la muerte y la extinción de la estirpe; la obscenidad que se relaciona con la incoherencia de sus rasgos se vincula con el desamparo de las potencias de lo luminoso y de lo oscuro, por lo dionisíaco y por lo apolíneo (Náter 300).

La introducción del caos en el orden determina el resto de la novela. Cuando Jerónimo recibe el regalo de la Peta Ponce se produce un hecho equivalente al poner el pie en la puerta para impedir que la cierren. Luego, con la concepción y nacimiento de Boy, la 
puerta del mundo ordenado se abre al caos y la dispersión. Con misiá Raquel convertida en sirvienta de su empleada y el influjo maligno de la Peta Ponce y la Perra Amarilla sobre Inés y también sobre su marido, el caos se convierte en un torrente imparable que termina con Inés enloquecida y Jerónimo convencido de su propia monstruosidad frente a la belleza y perfección física de su hijo.

De este modo, el mundo caótico de las nanas se toma el mundo de los patrones, "la sirvienta como otra encarnación del ama" (Sarrochi 166) instala la fealdad, la magia, la superstición y la locura en ese mundo perfecto y logra la disolución de la casta Azcoitía: Jerónimo muerto en extrañas y carnavalescas circunstancias, Inés vuelta loca y sacada de la Casa convertida en una vieja más de las que ahí habitaban, y el hijo monstruoso, incapaz de perpetuar el apellido, encerrado en una realidad de seres deformes como él, intentando olvidar los cinco días que vivió en la realidad exterior.

De este modo, queda establecido un nuevo discurso en el mundo de los servidos, una nueva verdad que se ha arraigado mediante el poder que tienen las nanas, un nuevo tipo de poder para este mundo luminoso que se ha degenerado. Se instala, entonces, lo que en términos de Foucault se denomina un nuevo "régimen de verdad" (198), ya que este pensador entiende que el poder crea o establece su verdad. De esta forma, se establece la verdad de quien detenta el poder: las nanas.

Para finalizar podríamos decir que el mundo del servicio dentro de esta novela tiene algunas características determinantes, como el poseer una especial cosmovisión, estar ligado a lo oscuro, mágico, incomprensible, feo, irracional y caótico -en abierta oposición al mundo de los patrones, bello, ordenado, racional y luminoso-, pero especialmente, tener un poder inmenso sobre sus patrones. Este poder, que es posible gracias a la carnavalización que permite invertir las jerarquías, les permite a las nanas llevar a la casta de los Azcoitía a su fin.

Vimos también que hay distintos tipos de inversión de las jerarquías, como la que representan la Brígida y Raquel, la de don Clemente y la María y la dada por la interpretación de la realidad en las distintas cosmovisiones.

Donoso nos presenta nanas con poder político, como la María Benítez, nanas con poder económico, como la Brígida, y con poder sobrenatural, como la Peta Ponce y la Perra Amarilla. Todas estas nanas y a las que ellas representan son capaces de llevar el caos y la anarquía al mundo ordenado de los patrones y, así, destruirlo usando las herramientas más temidas por la clase alta. De ahí su carácter maligno.

\section{BIBLIOGRAFÍA}

Amaro, Lorena. "Mito, silencio y poder en El obsceno pájaro de la noche". Anuario de Postgrado 2 (1997): 331-341.

Bajtín, Mijaíl. Problemáticas de la poética de Dostoievski. México D.F.: Fondo de Cultura Económica, 2005.

Bocaz, María Laura. "El des-dibujamiento de la Peta Ponce: Otra clave inédita de un delirio". Taller de Letras 37 (2005): 127-141. 
Bustillo, Carmen. Barroco y América Latina: Un itinerario inconcluso. Caracas: Monte Ávila Latinoamericana, 1990.

Colvin, Michael. Las últimas obras de José Donoso: Juegos, roles y rituales en la subversión del poder. Madrid: Pliegos, 2001.

Donoso, José. Donde van a morir los elefantes. Santiago: Alfaguara, 1999. . El obsceno pájaro de la noche. Santiago: Suma de letras, 2006.

Foucault, Michel. Microfisica del poder. Madrid: Las ediciones de La Piqueta, 1992.

García-Corales, Guillermo. Relaciones de poder y carnavalización en la novela chilena contemporánea. Santiago: Ediciones Asterión, 1995.

Gutiérrez Moaut, Ricardo. José Donoso: Impostura e impostación. La modelización lúdica y carnavalesca de una producción literaria. Gaithersburg: Ediciones Hispamérica, 1983.

Kristeva, Julia. Semiótica. Trad. José Martín Arancibia. Barcelona: Fundamentos, 1978.

Montecino, Sonia. Palabra dicha: Escritos sobre género, identidades, mestizaje. Santiago: Universidad de Chile, 6 noviembre 2009. Facso, Facultad de Ciencias Sociales, Universidad de Chile. http://www.facso.uchile.cl/publicaciones/biblioteca/docs/libros/palabra.pdf.

Náter, Miguel Ángel. José Donoso: Entre la Esfinge y la Quimera. Santiago: Cuarto Propio, 2007.

Sarrochi, Augusto. El simbolismo en la obra de José Donoso. Santiago: La Noria, 1992. 